\title{
Assessed Activity Relationship
}

National Cancer Institute

\section{Source}

National Cancer Institute. Assessed Activity Relationship. NCI Thesaurus. Code C153110.

Specifies the link between an assessment (performed observation) and the performed activity that the assessment is based on. 